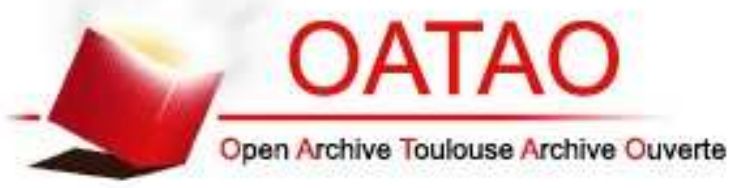

OATAO is an open access repository that collects the work of Toulouse researchers and makes it freely available over the web where possible.

This is an author-deposited version published in : http://oatao.univ-toulouse.fr/ Eprints ID : 9563

To link to this article : DOI: $10.1007 / \mathrm{s} 10750-013-1497-6$

URL : http://dx.doi.org/10.1007/s10750-013-1497-6

Open Archive TOULOUSE Archive Ouverte (OATAO)

To cite this version : De Nadaï-Monoury, Eve and Lecerf, Antoine and Canal, Julie and Buisson, Laetitia and Laffaille, Pascal and Gilbert, Franck A cost-effective method to quantify biological surface sediment reworking. (2013) Hydrobiologia, vol. $713\left(\mathrm{n}^{\circ} 1\right)$. pp. 115-125. ISSN 0018-8158 


\title{
A cost-effective method to quantify biological surface sediment reworking
}

\author{
Eve De Nadaï-Monoury • Antoine Lecerf • \\ Julie Canal - Laëtitia Buisson · Pascal Laffaille • \\ Franck Gilbert
}

\begin{abstract}
We propose a simple and inexpensive method to determine the rate and pattern of surface sediment reworking by benthic organisms. Unlike many existing methods commonly used in bioturbation studies, which usually require sediment sampling, our approach is fully non-destructive and is well suited for investigating non-cohesive fine sediments in streams and rivers. Optical tracer (e.g. luminophores or coloured sand) disappearance or appearance is assessed through time based on optical quantification of surfaces occupied by tracers. Data are used to calculate surface sediment reworking (SSR)
\end{abstract}

\author{
E. De Nadaï-Monoury · A. Lecerf · L. Buisson . \\ F. Gilbert $(\bowtie)$ \\ UPS, INP, EcoLab (Laboratoire écologie fonctionnelle et \\ environnement), Université de Toulouse, 118 route de \\ Narbonne, 31062 Toulouse Cedex 9, France \\ e-mail: franck.gilbert@univ-tlse3.fr \\ E. De Nadaï-Monoury · A. Lecerf · L. Buisson · \\ F. Gilbert \\ CNRS, EcoLab, 31055 Toulouse, France \\ J. Canal · P. Laffaille \\ INP, UPS, EcoLab (Laboratoire écologie fonctionnelle et \\ environnement), ENSAT, Université de Toulouse, \\ Avenue de l'Agrobiopole, 31326 Castanet Tolosan, \\ France \\ J. Canal · P. Laffaille \\ CNRS, EcoLab, 31326 Castanet Tolosan, France
}

coefficients depicting bioturbation intensities. Using this method, we evaluated reworking activity of stream organisms (three benthic invertebrates and a fish) in laboratory microcosms mimicking pool habitats or directly in the field within arenas set in depositional zones. Our method was sensitive enough to measure SSR as low as $0.2 \mathrm{~cm}^{2}$ day $^{-1}$, such as triggered by intermediate density $\left(774 \mathrm{~m}^{-2}\right)$ of Gammarus fossarum (Amphipoda) in microcosms. In contrast, complex invertebrate community in the field and a fish (Barbatula barabatula) in laboratory microcosms were found to yield to excessively high SSR $\left(>60 \mathrm{~cm}^{2}\right.$ day $\left.^{-1}\right)$. Lastly, we suggest that images acquired during experiments can be used for qualitative evaluation of species-specific effects on sediment distribution.

Keywords Bioturbation - Sediment reworking · Optical tracers · Benthic organism - Invertebrates · Fishes

\section{Introduction}

The role of organisms in ecosystem functioning is a central issue in the disciplines of ecology that seek to understand and assess the consequences of biodiversity and environmental changes on ecosystems. Stream ecosystem functioning is most often assessed through rates of transformation and transfer through food webs of carbon and energy by organisms (Palmer $\&$ Febria, 2012). Organisms also influence ecosystem 
functioning through non-trophic effects on benthic habitat properties which, however, remains difficult to quantify (Mermillod-Blondin \& Rosenberg, 2006; Marmonier et al., 2012; Statzner, 2012). Bioturbation is defined as the displacements of particles (sediment reworking) and solutes (ventilation) at the surface and below the surface sediment due to faunal activities (Kristensen et al., 2012). Multiple lines of evidence suggest that macrofauna, namely fish, tadpoles, and invertebrates can influence the distribution and properties of fine sediments deposited on stream bottoms (Zanetell \& Peckarsky, 1996; Moore, 2006; Creed et al., 2010; Marmonier et al., 2012; Sanpera-Calbet et al., 2012; Statzner, 2012).

Studies on particle bioturbation in lotic ecosystems have primarily sought to determine how and the extent to which benthic organisms and water flow interactively alter the deposition, mobilisation, and longitudinal transport of sediments along stream channels (Statzner, 2012). Benthic organisms, such as burrowers, can also affect vertical sediment distribution and transport in pools and habitats formed behind obstacles (rocks, debris dams) (Mermillod-Blondin \& Rosenberg, 2006). Low current velocity and shear stress in these depositional areas allow fine mineral and organic particles to settle and benthic organisms are likely to be the main geomorphic agent. Moreover, in such hotspots of plant litter accumulation and invertebrate production (Huryn \& Wallace, 1987; Friberg \& Larsen, 1998; Dangles, 2002), bioturbating organisms may also affect ecosystem functioning through indirect effects on particulate organic matter processing (Aller, 1988; Mermillod-Blondin \& Rosenberg, 2006; Navel et al., 2012). For instance, the bioturbation activity of invertebrates can uncover buried leaf litter resulting in accelerated litter consumption by invertebrate shredders (Creed et al., 2010).

Fine sediment bioturbation can be quantified using different approaches (see review by Maire et al., 2008). The 1-D (e.g. Sun et al., 1991; MermillodBlondin et al., 2004; Schmidt et al., 2007) and 2-D (Gilbert et al. 2003; Solan et al., 2004) tracer methods are the most popular approaches used in field or laboratory studies in soil and marine research. Because these methods are based on sediment coring and slicing prior to vertical tracer quantification, they are mostly applicable to fine cohesive sediments. In addition, they may not be sensitive enough to quantify sediment reworking activity of small stream organisms which are unlikely to affect sediment redistribution far below the surface. Alternatively, surface imaging techniques have been proposed to assess horizontal animal displacements and activity traces at the sediment surface (e.g. Hollertz \& Duchene, 2001; Maire et al., 2007; Dafoe et al., 2011; Robert \& Juniper, 2012). Such approaches are only marginally used, however, due to the expensive video/telemetric equipment required and inherent logistic limitations. In the present paper, we present a new method to quantify surface sediment reworking in depositional zones, which combines the simplicity and cost-effectiveness of tracer methods and the versatility and nondestructive nature of surface imaging techniques. It was applied to evaluate sediment reworking activity of a range of stream organisms (three invertebrates and a fish species) in laboratory microcosms mimicking pool habitats or directly in the field within arenas set in streams.

\section{Materials and methods}

General principles of the method

The method is based on the quantification of surface sediment reworking using inert particulate tracers. We propose to use either fluorescent (luminophores; Partrac Ltd.) or non-fluorescent (dark blue sand purchased from ornamental fish-keeping shop) coloured particles. Tracer size range should be chosen to match the grain size distribution of sediments in experimental units (Table 1). The relative position of the tracer layers and non-tracer particles determines whether appearance or disappearance of tracers is assessed (Fig. 1). Tracer appearance is assessed when the tracer layer is embedded in sediment subsurface whereas quantification of tracer disappearance just requires tracers to be sprinkled on the sediment surface. In both cases, the tracer layer has to be reasonably thin ( $\sim 2 \mathrm{~mm}$ thick) and uniformly distributed over the surface of sediments. The top layer of either tracers (disappearance method) or sediments (appearance method) should not be too thin so as to limit particle displacement due to handling. However, surface sediment reworking cannot be accurately quantified if the thickness of this top layer largely 


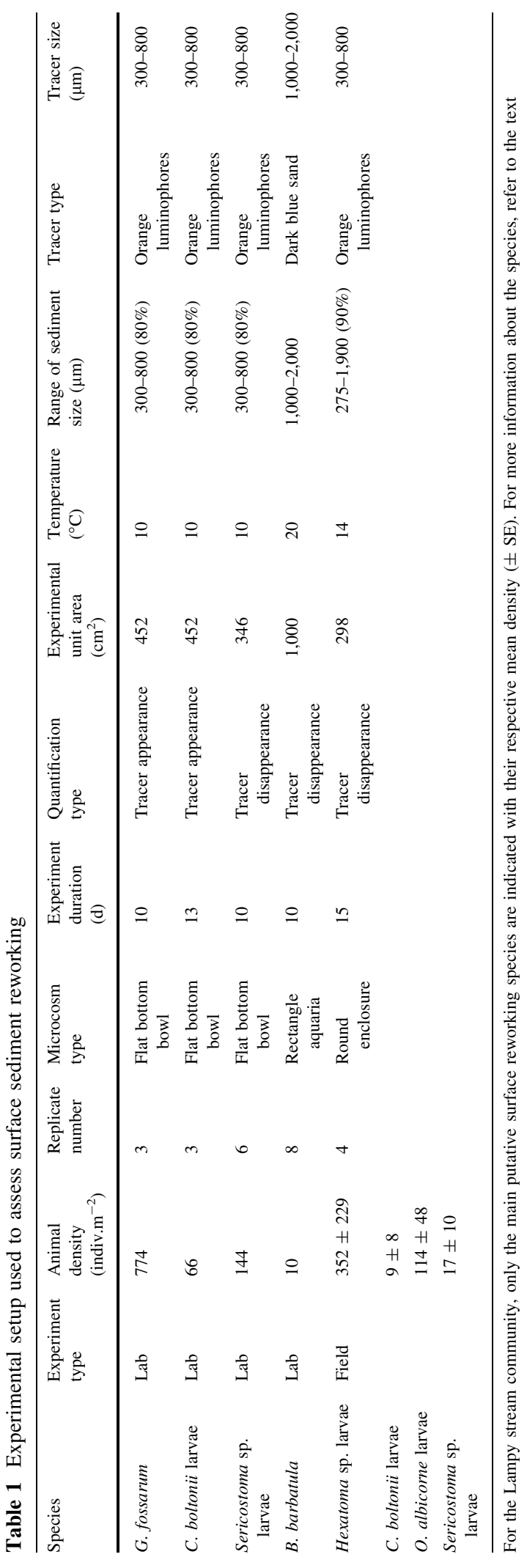

exceeds the maximum depth of animal traces and burrows.

Optical quantification allows determining the surface occupied by tracers at any time. This nondestructive approach causes minimal disturbance to microcosms, allowing repeated measurements over time. In addition, it does not require purchasing expensive or specific equipment. Here, we used a consumer digital camera (Canon EOS 20D) mounted on a tripod which can be moved from one experimental unit to another. Pictures of sediment surface are taken under ambient light when non-fluorescent coloured sand is used. The use of a portable ultraviolet lamp $(\lambda: 365 \mathrm{~nm})$ under dark conditions is required for fluorescent luminophores. Pictures are processed using image analysis software such as Image—Pro Plus (MediaCybernetics, Inc.) or Image $\mathbf{J}$ (National Institutes of Health, http://rsb.info.nih.gov/ ij/). Image channels are first split into RGB (RedGreen-Blue) or HSV (Hue-Saturation-Value) colour, and the channel best distinguishing between "tracer pixels" and "sediment pixels" is then selected. In our experiments, the red and hue channels were selected for orange luminophores and dark blue sand, respectively. Pre-processed images are then thresholded and binarized to separate the two pixel types. Automatic pixel counts are then performed to estimate the surface occupied by tracers. The remaining area formed by non-tracer particles (sediment) is calculated as the difference between total surface area of microcosms minus surface occupied by tracers. The surface occupied by tracers (appearance quantification) or by sediment particles (disappearance quantification) is assessed over time to determine sediment reworking rate. Values for microcosms with organisms can be corrected by sediment disturbance due to microcosm handling using controls. Rate of surface sediment reworking (SSR, expressed in $\mathrm{cm}^{2} \mathrm{day}^{-1}$ ) in each microcosm is given by the slope of the least square regression line of surface reworked $\left(\mathrm{cm}^{2}\right)$ against time (days).

Experimental tests

\section{Laboratory experiments}

We determined surface sediment reworking rate of four taxonomically disparate organisms expected to influence the distribution and reworking of deposited 
Fig. 1 Schematic representation of the principle of the two tracer quantification methods: appearance (left) and disappearance (right) of tracers. Lateral views show the positioning of the different material layers and top views at the start $\left(T_{0}\right)$ and during experiment $\left(T_{x}\right)$

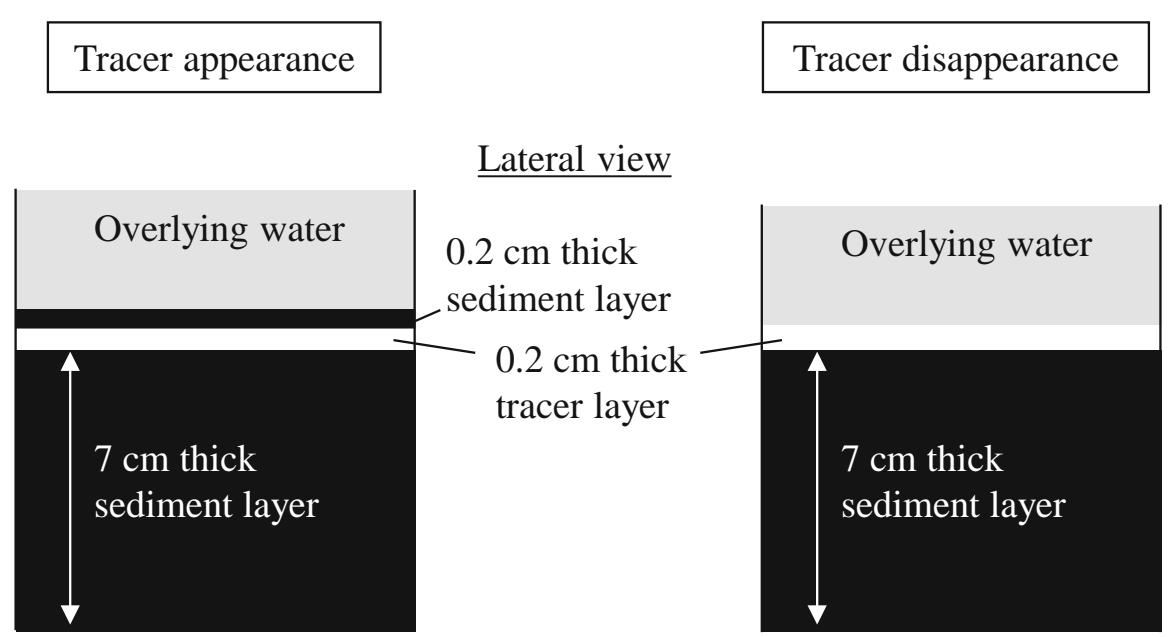

\section{$\underline{\text { Top view }}$}

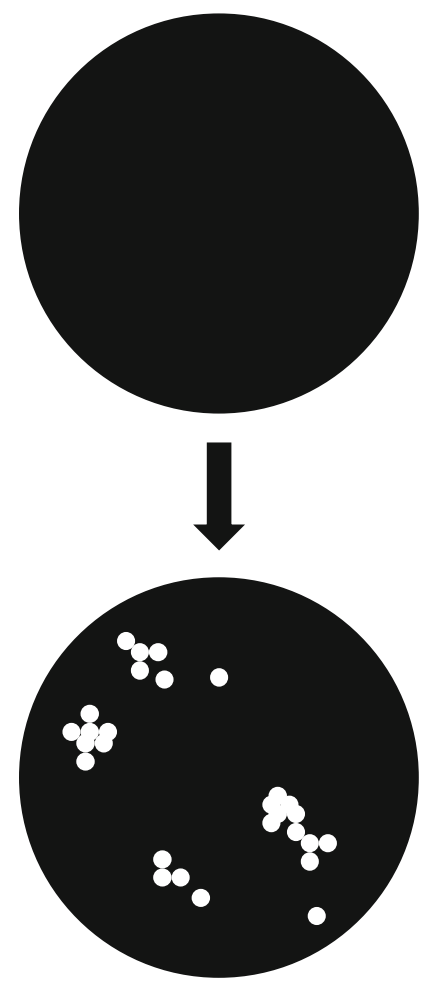

sediments in streams through different ways. The amphipod crustacean Gammarus fossarum (Koch, 1835 ) is an invertebrate (up to $2 \mathrm{~cm}$ long) with fast swimming ability. This omnivorous species often occurs at very high densities in streams relying on terrestrial leaf litter as the main energy source. Despite weak burrowing abilities, G. fossarum may disturb fine-deposited sediments through the permanent movement and foraging activity of a large number of individuals. The cased-caddisfly larva Sericostoma sp. is a common, $1-2 \mathrm{~cm}$ long invertebrate shredder inhabiting depositional zones. It potentially affects fine sediment distribution through its burrowing behaviour and use of sand to build its case. The dragonfly Cordulegaster boltonii (Donovan, 1807) larva is a sit-and-wait predator which buries its body in 
the sediment and wait motionless for capturing prey with its extendable jaws. Due to its body size (up to $4 \mathrm{~cm}$ long) and frequent change of hunting site, sediment reworking by this species may be considerable. The stone loach (Barbatula barbatula L., 1758) is a fish (mean length of individuals used in the present experiment: $10 \mathrm{~cm}$ ) inhabiting streams with gravel and sandy bottoms. It buries in sediment to hide and feeds by sucking in large amounts of sediment, extracting small benthic invertebrates and releasing the sediment. Invertebrates (G. fossarum, Sericostom$a$, and $C$. boltonii) were sieve-collected in depositional zones in low-order forested streams located in the Montagne Noire (South-Western France). The larger individuals available at collection, generally mid-tolate stages, were kept for our experiments. Stone loaches were collected by electrofishing in the Saudrune River (South-Western France).

A week prior experiments, organisms were kept in aquaria containing sediment and water from the sampling sites, in a temperature controlled room under a 12:12 h light regime. Temperature was set close to values encountered in the streams at the time of organism collection $\left(10{ }^{\circ} \mathrm{C}\right.$ for invertebrate and $20{ }^{\circ} \mathrm{C}$ for the fish; Table 1). Organisms were then placed in microcosms filled with sediment and aerated stream water and supplied with food resources. Laboratory microcosms were flat bottom plastic bowls ( $24 \mathrm{~cm}$ diameter and $15 \mathrm{~cm}$ high) for invertebrates, and opaque glass aquaria $(40 \mathrm{~cm}$ long, $25 \mathrm{~cm}$ wide, $25 \mathrm{~cm}$ high), for fish. G. fossarum and Sericostoma were supplied with four alder leaves incubated 5 days in a stream to allow microbial conditioning. C. boltonii were supplied with 40 living G. fossarum amphipods. B. barbatula were supplied with dead Chironomus sp. concealed in the sediment. Organism density in microcosms ranged from 66 to 972 indiv. $^{-2}$ for invertebrates and 10 indiv. $\mathrm{m}^{-2}$ for the fish. These densities were generally higher than natural densities determined at the stream level but were consistent with patch-scale densities often observed at low discharge period. Animal mortality was recorded at the end of each experiment; in addition, invertebrate preys used in the experiment with $C$. boltonii were counted daily.

The bottom of microcosms was filled with a 5- to 7 -cm thick layer of sandy substrate (Table 1). For the experiments with invertebrates, dry sand deposited in an oxbow (Garonne River), was sieved on a 2-mm mesh screen and frozen to kill any remaining fauna.
For the experiment with fish, we used commercial white quartz sand (Table 1). A 2-mm layer of tracers (orange luminophores or dark blue sand) were then added either on sediment surface or subsurface (Table 1; Fig. 1). Filtered stream water was dripped into microcosms, avoiding sediment disturbance. Water depth did not exceed $4 \mathrm{~cm}$ in invertebrate microcosms and $20 \mathrm{~cm}$ in fish microcosms to ensure the diffusion of atmospheric oxygen throughout the water column and thus limit oxygen depletion at sediment surface. Experiments also include three control microcosms, without organisms, to quantify tracer displacements due to handling or gravity. Pictures were taken daily directly above each microcosm under appropriate lightning. Leaves in microcosms with G. fossarum and Sericostoma (including corresponding controls without animals) were removed cautiously before and replaced right after image capture.

\section{Field experiment}

A field experiment was performed in a natural stream to assess sediment reworking rate of multispecies assemblages under realistic settings. The Lampy stream (Montagne Noire, South-Western France), a low-order, cold, soft water streams, was chosen for its diverse invertebrate communities and the presence of large depositional zones made of sandy substrates. In summer (i.e. low-flow period), current velocity was negligible (i.e. $5 \mathrm{~cm} \mathrm{~s}^{-1}$ ) in pools. Larvae of Hexatoma (cranefly, Diptera), C. boltonii (dragonfly, Odonata), Odontocerum albicorne (caddisfly, Tricoptera; Scopoli, 1763) and Sericostoma sp. (caddisfly, Tricoptera) were the main putative sediment reworking species (Table 1). A $298 \mathrm{~cm}^{2}$ surface of each of the four depositional zones selected for this study was confined within an experimental enclosure made of a PVC pipe $(20 \mathrm{~cm}$ diameter and $30 \mathrm{~cm}$ high) set vertically, inserted $7 \mathrm{~cm}$ deep into the sediment and secured with iron sticks. A $2 \mathrm{~cm}$ high $\times 20 \mathrm{~cm}$ long opening was cut out the pipes and was covered by a $500 \mu \mathrm{m}$ nylon mesh net to ensure water exchange. Openings were oriented facing downstream; the fine mesh net acting as a shield against excessive inputs of fine sediments and strong water flows which might have occurred after heavy rains. A thin $(\sim 2 \mathrm{~mm})$ layer of orange luminophores was added at the beginning of the experiment. Pictures were taken 
above each microcosm every 3-4 days. Dark condition required for the use of the UV light was ensured by wrapping a light shade cloth over the microcosm and camera. At the end of the experiment, sediments inside each enclosure were sampled (over $7 \mathrm{~cm}$ depth) to sort and identify macrofauna. To control for luminophores' displacement in the absence of fauna, batches of natural sediments from the Lampy streams were returned to the laboratory. After being frozen to kill fauna, the sediment was used to set control microcosms and processed at the laboratory in the same manner as in experiments with invertebrates.

\section{Statistics}

Ordinary least-squares regressions were performed in R (R Development Core Team, 2011) to estimate the rates of surface sediment reworking in all experiments.

\section{Results}

While no sediment reworking occurred in controls without animals throughout the whole experiment (data not shown), disturbances were detected shortly after animals were introduced in microcosms (day 0). After 4 days, mean surface reworked ranged from $0.7 \mathrm{~cm}^{2}(0.1 \%$ of the total experiment surface) for $G$. fossarum to $254 \mathrm{~cm}^{2}(25.4 \%)$ for $B$. barbatula (Fig. 2). Surface of sediment reworked increased linearly with time and the rate of change gradually declined until ca. $75 \%$ of microcosm surface was reworked (Fig. 2). The break in the slope arose at day 6 in the B. barbatula experiment (Fig. 2D). In contrast, we found fairly linear increase in surface reworked in microcosms with G. fossarum (Fig. 2A), C. boltonii (Fig. 2B) and Sericostoma (Fig. 2C) throughout experiments. In the experiment with $C$. boltonii, the number of $G$. fossarum declined sharply and no prey remained after 10 days, suggesting that the unchanged sediment reworking measured for the last 3 days of the experiment was only due to dragonfly larvae. In addition, rate of sediment reworking by $G$. fossarum was sufficiently low (Table 2) to assume that bioturbation was determined by $C$. boltonii, not its prey. During the field experiment, a threshold becomes apparent only 4 days after the beginning of the field experiment assessing biological reworking ability of complex communities $\left(240 \mathrm{~cm}^{2}\right.$;
$85 \%$; Fig. 2E). Surface sediment reworking coefficient was estimated as the slope of the regression line of surface reworked versus days fitted to the initial linear part of each curve (Table 2). High $R$-square values $\left(R^{2}>0.78\right)$ confirmed the adequacy of the linear regression model. Surface sediment reworking coefficient ranged across $>2$ orders of magnitude, i.e. from 0.2 to $60 \mathrm{~cm}^{2}$ day $^{-1}$ in the G. fossarum and $B$. barbatula experiments, respectively (Table 2). Interspecific differences in sediment reworking abilities become even more apparent when considering a per capita SSR (Table 2).

In addition to difference in rates of sediment reworking, species were also found to differ in terms of surface sediment reworking pattern (Fig. 3). G. fossarum (Fig. 3A) and B. barbatula (Fig. 3E) disturbed sediment particles in a fairly uniform manner, especially when compared to the patchy sediment disturbances caused by C. boltonii (Fig. 3B). Sericostoma created reticulated furrow pattern of traces (Fig. 3D). Images of the field experiment suggest that any of the three types of sediment reworking pattern dominate in natural communities consisting of a mixture of different species.

\section{Discussion}

In spite of broad recognition that benthic organisms can influence the displacement, distribution pattern, and properties of sediments in freshwaters, research in this field has been curbed by the intricate interactions between biological and physical processes as well as methodological difficulties (Covich et al., 1999; Mermillod-Blondin \& Rosenberg, 2006; Statzner, 2012). The method presented in this paper is likely to be a valuable tool for studying sediment reworking at various scales, from individuals to communities. Specifically, it allows to efficiently assessing the effects of benthic organisms on any type of sediment. In comparison, the "traditional" vertical sediment reworking quantification methods using tracers (e.g. Gerino et al., 1998; Berg et al., 2001; Gilbert et al., 2007), routinely used in marine fine sediment, are based on core sampling and, therefore, become unreliable in non-cohesive, coarse sediments (due to reduced resolution of slicing and vertical movements of tracers during slicing procedure). Shifting focus from deep to surface sediment reworking is also 

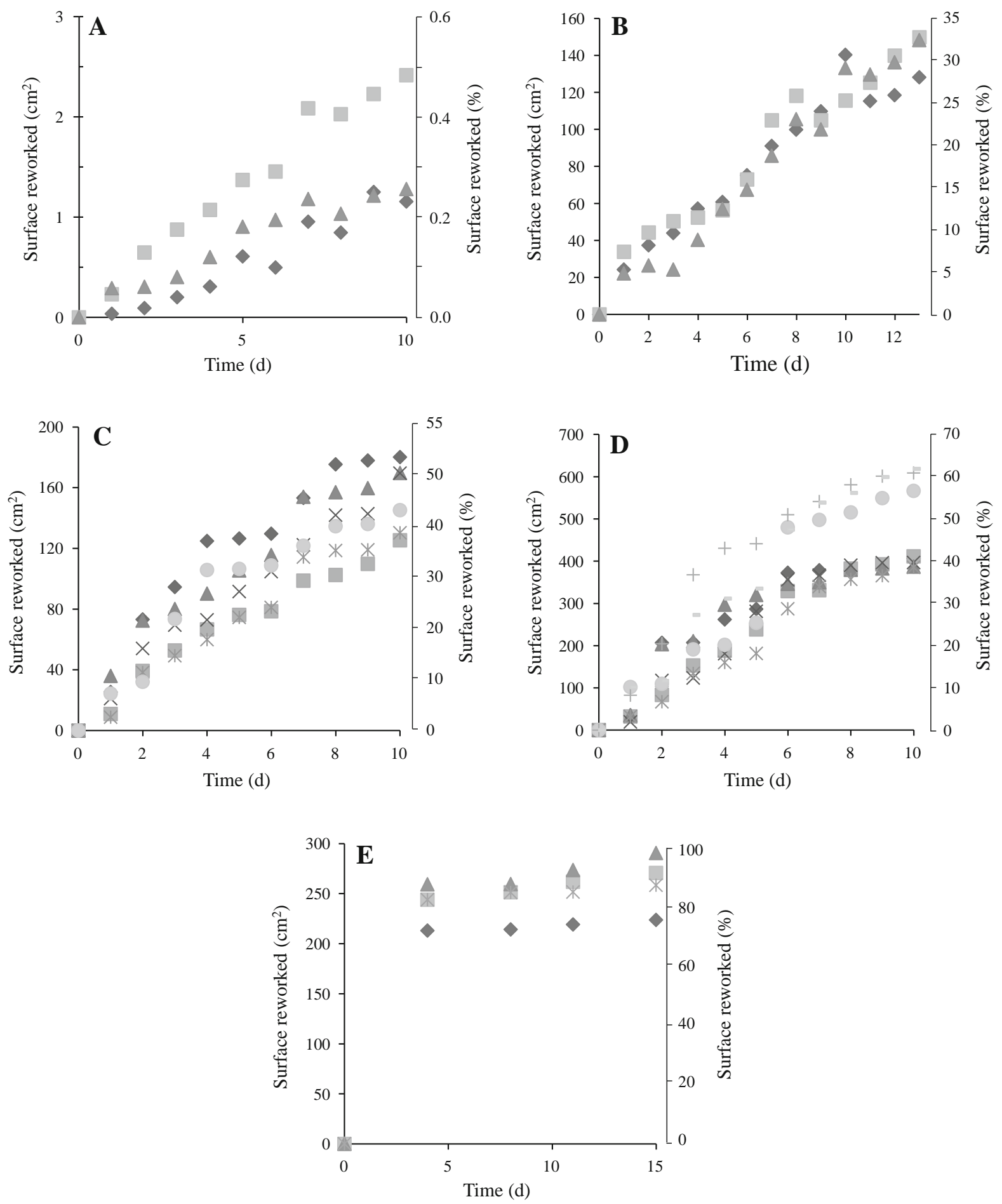

Fig. 2 Surface sediment reworked (in $\mathrm{cm}^{2}$ and percentage of the total surface) against time, given for each experimental unit of five experiments. The different symbols represent replicates. A G. fossarum $(n=3)$, B C. boltonii $(n=3)$, C Sericostoma $\mathrm{sp.}$ $(n=6), \quad \mathbf{D}$ B. barbatula $(n=8)$ and $\mathbf{E}$ Lampy stream community (in situ experiment) $(n=4)$. Details on experimental setup are given in Table 1. Note that scales are not the same 
Table 2 Surface sediment reworking (SSR) coefficient $\left(\mathrm{cm}^{2}\right.$ day $\left.{ }^{-1}\right)$ determined as the slope of the regression line of surface reworked $\left(\mathrm{cm}^{2}\right)$ versus days

\begin{tabular}{lcccc}
\hline Species or community & SSR $\left(\mathrm{cm}^{2}\right.$ day $\left.^{-1}\right)$ & $\begin{array}{l}\text { Linear trend } \\
\text { period (days) }\end{array}$ & $\begin{array}{l}R^{2} \text { coefficient } \\
\text { range }\end{array}$ & $\begin{array}{l}\text { SSR per capita } \\
\left(\mathrm{cm}^{2} \text { day }^{-1}\right)\end{array}$ \\
\hline G. fossarum & $0.2 \pm 0.1$ & 10 & $0.91-0.98$ & $6.25 \times 10^{-3}$ \\
C. boltonii larvae & $11.8 \pm 0.3$ & 13 & $0.89-0.98$ & 3.93 \\
Sericostoma sp. larvae & $17.1 \pm 2.8$ & 10 & $0.78-0.98$ & 3.42 \\
B. barbatula & $63.5 \pm 15.1$ & 6 & $0.87^{+}-0.98$ & 63.5 \\
Lampy stream community & $60.0 \pm 4.2$ & 4 & 1 & $\mathrm{NC}$ \\
\hline
\end{tabular}

Only data along the initial linear portion of curve was kept for calculations. As a single data point for the field experiment met the inclusion criteria, SSR was estimated as the slope of the regression line through the origin and R-square was thus equal to one. Mean SSR values by experiment are given. SE and the range of R-square depict variability across experimental units. Per capita, SSR was calculated as the ratio of SSR to animal number in microcosms in laboratory experiments. It was not calculated (NC) for the Lampy stream community

Note Linear regression models were all significant $(p<0.001$, except * for which $p<0.01)$

warranted when studying shallow sediment habitats, such as depositional zones in streams which are primarily colonized by epibenthic fauna. As shown in this study, organisms do not need to move deep into the sediments to cause detectable sediment disturbance in streams (Statzner, 2012).

Perhaps the main strength of the method proposed here lies in its simplicity and cost-effectiveness. Coloured sand, a digital camera, and accessories (UV light, tripod) were sufficient to quantify surface sediment disturbances by a range of animals of contrasting body size and behaviour. For instance, $G$. fossarum seems to have by far the weakest surface sediment reworking ability, as each individual disturbed only a few sand grains every day, yet cumulative reworked surface followed a clear linear increase through time. It is worth noting, however, that our study was not designed to assess interspecific variability of sediment reworking rate and difference in experimental conditions (e.g. temperature, tracer size, organisms' density) may also partly explain variations in per capita SRR values reported here (Table 2). Detection sensitivity is probably higher when tracers are embedded in the sediment and tracer appearance is measured as in the G. fossarum experiment. This is because the appearance of a few tracer particles can be better detected on a dark background (natural sediment) whereas the disappearance of a few tracer particles from a saturated (coloured) background may not be accurately quantified especially due to halo surrounding fluorescent tracers. Nevertheless, both appearance and disappearance quantifications were found to yield convergent estimates for surface sediment reworking rates in a comparative experiment with amphipods (3.44 \pm 0.3 and $3.42 \pm$ $0.2 \mathrm{~cm}^{2} \mathrm{day}^{-1}$ for appearance and disappearance; mean $\pm \mathrm{SD} ; n=2$ : data not shown). The choice of methods should also be based on practical considerations. The disappearance method is perhaps the best option for field studies due to its extreme simplicity and the lowest disturbance caused to benthic community compared with the appearance method that requires adding two successive layers of particles (tracers + sand).

Contrary to sophisticated mapping tools (e.g. laser telemeters) restricted to well-controlled environments (e.g. Maire et al., 2007) or to complex and expensive seafloor observatories (Robert \& Juniper, 2012), methods using optical tracers can be easily used under field conditions. In addition, to evaluate the ecosystemlevel significance of bioturbation, field studies could also be carried out to assess ecosystem health (Palmer $\&$ Febria, 2012). There is evidence that sedimentation, water pollution, and human-driven biodiversity loss can affect the rate of sediment reworking (e.g. Mazik \& Elliott, 2000; Mulsow et al., 2002; Lagauzère et al., 2009). Our field results indicate that biological activity can sustain high rate of surface sediment reworking in the depositional zones of pristine streams. However, caution is needed when drawing generality from our findings because faunal activity might have been affected by the use of enclosures to isolate study patches. When water flow is negligible, such as in the present study, the use of arenas is recommended because of advantages such as patch delineation and improving dark conditions (necessary to take pictures under UV light). 
Fig. 3 Samples of sediment surface images taken from five experiments. A $G$. fossarum, B C. boltonii, C Lampy stream community (in situ experiment),

D Sericostoma sp. and $\mathbf{E} B$. barbatula experiment. Black pixels represent tracers. Details on experimental setup are given in Table 1
A

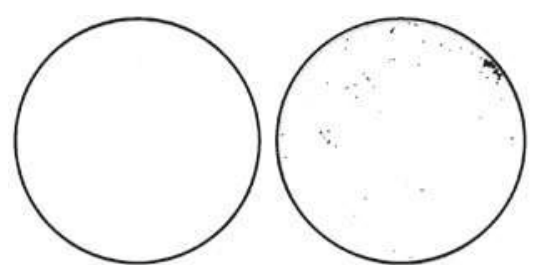

B Day 0 Day 4

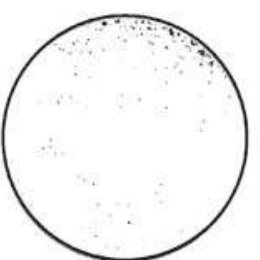

Day 8

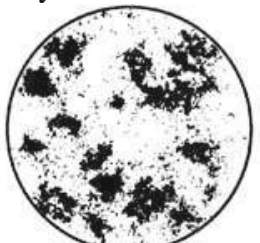

Day 8

C

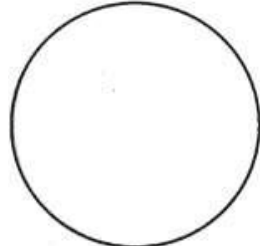

Day 0

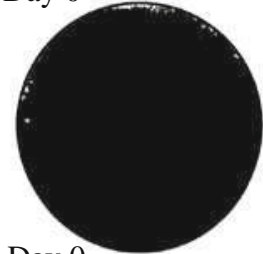

Day 0

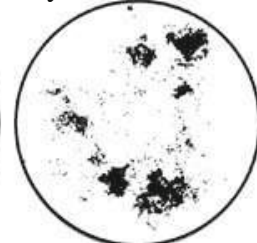

Day 4

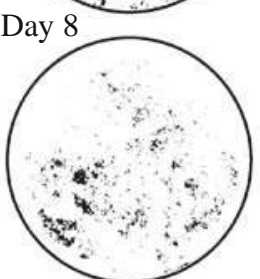

Day 8

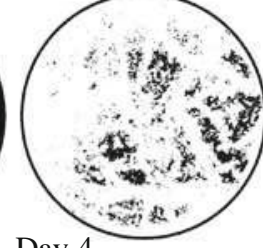

D
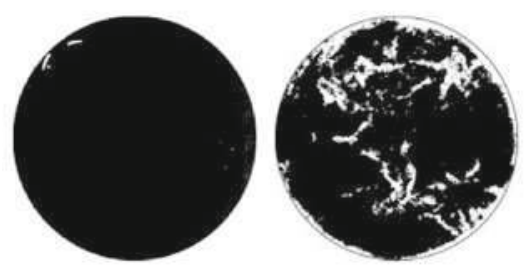

Day 0

Day 4

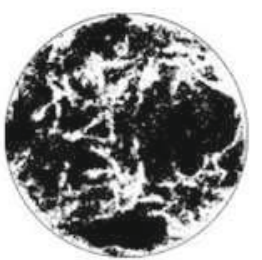

Day 8 Day 10

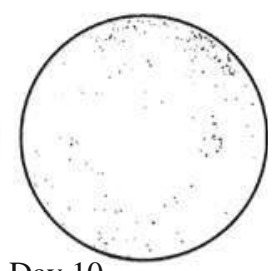

Day 10

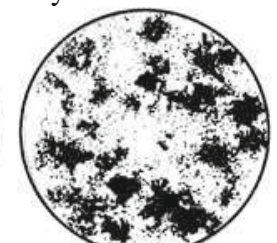

Day 11

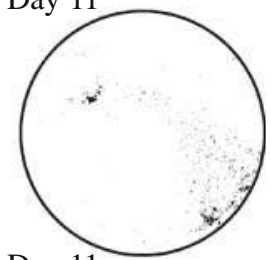

Day 11

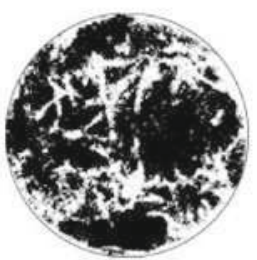

Day 10

$\mathbf{E}$
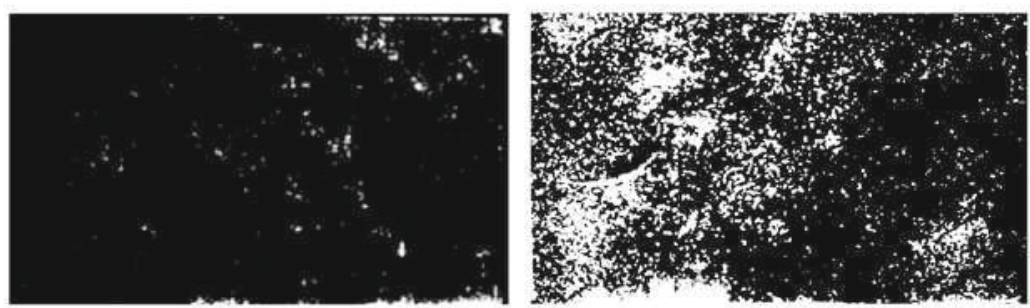

Day 0

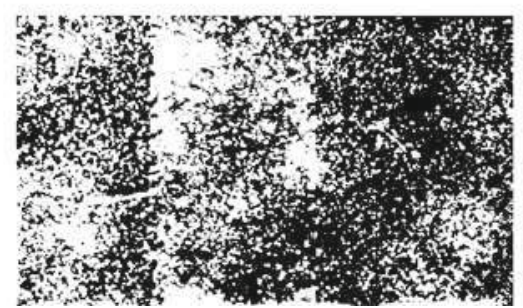

Day 4

Day 10

Our method provides only estimation of instantaneous bioturbation rate since the integration of sediment disturbances through time is limited to the initial linear portion of the relationship of surface reworked versus time. In our experimental design (i.e. species and densities used), surface sediment reworking occurred at a constant rate for roughly 1 week. Above $75 \%$ of surface reworked, tracers and sediments become well mixed so that further sediment disturbance cannot be quantified accurately. The occurrence 
of such a threshold has important implication for the design of experiments. As illustrated by the lack of initial data (no picture taken between day 0 and day 4) in the field experiment, the time step for image acquisition must not be too large otherwise the initial linear portion cannot be accurately captured. In all studies cases presented here, daily image capture seemed to be the most appropriate time step.

Images acquired during experiments may be used for qualitatively evaluation of species-specific effects on sediment distribution. Different disturbance patterns can simply be determined based on visual inspection of pictures (Fig. 3). Such an approach has already been used to define five major categories of reworking organisms in cohesive sediments using vertical reworking quantification (François et al. 2001). Likewise, functional groups may be determined based on surface reworking pattern. Patch-makers are organisms with burrowing abilities, such as $C$. boltoni, generating patches of disturbed sediment. Furrowmakers are typically crawling species which make furrow network into sediment with their own body, case (Sericostoma) or shell. Swimmers (G. fossarum and $B$. barbatula) are likely to affect sediment surface in a more uniform manner. Before going further into the definition of such groups, this method of quantification has to be used with more species in a range of habitats. Spatial analyses of sediment reworking (e.g. spatial point patterns analyses) could also be performed to gain greater insight into animal behaviour and its relationship with bottom sediment.

\begin{abstract}
Acknowledgements Authors are grateful for the help provided by Séverine Jean during fish field experiment. Thanks are also due to the associate editor and anonymous reviewers for their insightful comments which improved the manuscript. This work was supported by the Conseil Régional Midi-Pyrénées in the frame of the Action Interrégionale Aquitaine \& Midi-Pyrénées "GAGILAU", by the French ANR programme "ADAPT'EAU" (project ANR-11-CEPL008), and by the "Biodiversity and Forest Management" programme (project SYLECOL) funded by the French Ministry of Environment. This paper is the Nereis Park contribution number \#34.
\end{abstract}

\section{References}

Aller, R. C., 1988. Benthic fauna and biogeochemical processes in marine sediments: the role of burrow structures. In Blackburn, T. H. \& J. Sørensen (eds), Nitrogen Cycling in Marine Environments. Wiley, New-York: 301-338.
Berg, P., S. Rysgaard, P. Funch \& M. K. Sejr, 2001. Effects of bioturbation on solutes and solids in marine sediments. Aquatic Microbiology Ecology 26: 81-94.

Covich, A. P., M. A. Palmer \& T. A. Crowl, 1999. The role of benthic invertebrate species in freshwater ecosystems. BioScience 49: 119-127.

Creed, R. P., A. Taylor \& J. R. Pflaum, 2010. Bioturbation by a dominant detritivore in a headwater stream: litter excavation and effects on community structure. Oikos 119: 1870-1876.

Dafoe, L. T., A. L. Rygh, B. Yang, M. K. Gingras \& G. Pemberton, 2011. A new technique for assessing tubificid burrowing activities, and recognition of biogenic grading formed by these oligochaetes. Palaios 26: 66-80.

Dangles, O., 2002. Aggregation of shredder invertebrates associated with benthic detrital pools in seven headwater forested streams. Verhandlungen - Internationale Vereinigung für theoretische und angewandte Limnologie 28: $1-4$.

François, F., J.-C. Poggiale, J.-P. Durbec \& G. Stora, 2001. A new model of bioturbation for a functional approach to sediment reworking resulting from macrobenthic communities. In Aller J. Y., S. A. Woodin, R. C. Aller (eds), Organism-Sediment Interactions, Vol. 21. University of South Carolina, The Belle W. Baruch Library in Marine Science, Columbia: 73-86.

Friberg, N. \& S. E. Larsen, 1998. Microhabitat selection by stream invertebrates: importance of detritus aggregations. Verhandlungen - Internationale Vereinigung für theoretische und angewandte Limnologie 26: 1016-1020.

Gerino, M., R. C. Aller, C. Lee, J. K. Cochran, J. Y. Aller, M. A. Green \& D. Hirschberg, 1998. Comparison of different tracers and methods used to quantify bioturbation during a spring bloom: 234-Thorium, luminophores and Chlorophyll a. Estuarine, Coastal and Shelf Science 46: 531-547.

Gilbert, F., S. Hulth, N. Strömberg, K. Ringdahl \& J.-C. Poggiale, 2003. 2-D optical quantification of particle reworking activities in surface marine sediments. Journal of Experimental Marine Biology and Ecology 285(286): 251-263.

Gilbert, F., S. Hulth, V. Grossi, J.-C. Poggiale, G. Desrosiers, R. Rosenberg, M. Gérino, F. François-Carcaillet, E. Michaud \& G. Stora, 2007. Sediment reworking by marine benthic species from the Gullmar Fjord (Western Sweden): importance of faunal biovolume. Journal of Experimental Marine Biology and Ecology 348: 133-144.

Hollertz, K. \& J. C. Duchene, 2001. Burrowing behaviour and sediment reworking in the heart urchin Brissopsis lyrifera Forbes (Spatangoida). Marine Biology 139: 951-957.

Huryn, A. D. \& J. B. Wallace, 1987. Local morphology as a determinant of macrofaunal production in a mountain stream. Ecology 68: 1932-1942.

Kristensen, E., G. Penha-Lopes, M. Delefosse, T. Valdemarsen, C. O. Quintana \& G. T. Banta, 2012. What is bioturbation? The need for a precise definition for fauna in aquatic sciences. Marine Ecology Progress Series 446: 285-302.

Lagauzère, S., P. Boyer, G. Stora \& J. M. Bonzom, 2009. Effects of uranium-contaminated sediments on the bioturbation activity of Chironomus riparius larvae (Insecta, Diptera) and Tubifex tubifex worms (Annelida, Tubificidae). Chemosphere 76: 324-334. 
Maire, O., J. C. Duchene, L. Bigot \& A. Gremare, 2007. Linking feeding activity and sediment reworking in the depositfeeding bivalve Abra ovata with image analysis, laser telemetry and luminophore tracers. Marine Ecology Progress Series 351: 139-150.

Maire, O., P. Lecroart, F. J. R. Meysman, R. Rosenberg, J. C. Duchene \& A. Gremare, 2008. Methods of sediment reworking assessment in bioturbation research: a review. Aquatic Biology 2: 219-238.

Marmonier, P., G. Archambaud, N. Belaidi, N. Bougon, P. Breil, E. Chauvet, C. Claret, J. Cornut, T. Datry, M.-J. DoleOlivier, B. Dumont, N. Flipo, A. Foulquier, M. Gérino, A. Guilpart, F. Julien, C. Maazouzi, D. Martin, F. MermillodBlondin, B. Montuelle, P. Namour, S. Navel, D. Ombredane, T. Pelte, C. Piscart, M. Pusch, S. Stroffek, A. Robertson, J.-M. Sanchez-Pérez, S. Sauvage, A. Taleb, M. Wantzen \& P. Vervier, 2012. The role of organisms in hyporheic processes: gaps in current knowledge, needs for future research and applications. Annales de Limnologie International Journal of Limnology. 48: 253-266.

Mazik, K. \& M. Elliott, 2000. The effects of chemical pollution on the bioturbation potential of estuarine intertidal mudflats. Helgoland Marine Research 54: 99-109.

Mermillod-Blondin, F. \& R. Rosenberg, 2006. Ecosystem engineering: the impact of bioturbation on biogeochemical processes in marine and freshwater benthic habitats. Aquatic Sciences 68: 434-442.

Mermillod-Blondin, F., R. Rosenberg, F. François-Carcaillet, K. Norling \& L. Mauclaire, 2004. Influence of bioturbation by three benthic infaunal species on microbial communities and biogeochemical processes in marine sediment. Aquatic Microbial Ecology 36: 271-284.

Moore, J. W., 2006. Animal ecosystem engineers in streams. BioScience 56: 237-246.

Mulsow, S., P. F. Landrum \& J. A. Robbins, 2002. Biological mixing responses to sublethal concentrations of DDT in sediments by Heteromastus filiformis using a ${ }^{137} \mathrm{Cs}$ marker layer technique. Marine Ecology Progress Series 239: 181-191.
Navel, S., F. Mermillod-Blondin, B. Montuelle, E. Chauvet \& P. Marmonier, 2012. Sedimentary context controls the influence of ecosystem engineering by bioturbators on microbial processes in river sediments. Oikos 121: 1134-1144.

Palmer, M. A. \& C. A. Febria, 2012. The heartbeat of ecosystems. Science 336: 1393-1394.

R Development Core Team, 2011. R: A language and environment for statistical computing. R Foundation for Statistical Computing, Vienna.

Robert, K. \& S. K. Juniper, 2012. Surface-sediment bioturbation quantified with cameras on the NEPTUNE Canada cabled observatory. Marine Ecology Progress Series 453: 137-149.

Sanpera-Calbet, I., E. Chauvet \& J. Richardson, 2012. Fine sediment on leaves: shredder removal of sediment does not enhance fungal colonisation. Aquatic Sciences 74: 527-538.

Schmidt, S., J. M. Jouanneau, O. Weber, P. Lecroart, O. Radakovitch, F. Gilbert \& D. Jezequel, 2007. Sedimentary processes in the Thau Lagoon (South France): from seasonal to century time scales. Estuarine, Coastal and Shelf Science 72: 534-542.

Solan, M., B. D. Wigham, I. R. Hudson, R. Kennedy, C. H. Coulon, K. Norling, H. C. Nilsson \& R. Rosenberg, 2004. In situ quantification of bioturbation using time-lapse fluorescent sediment profile imaging (f-SPI), luminophore tracers and model simulation. Marine Ecology Progress Series 271: 1-12.

Statzner, B., 2012. Geomorphological implications of engineering bed sediments by lotic animals. Geomorphology 157: 49-65.

Sun, M.-Y., R. C. Aller \& C. Lee, 1991. Early diagenesis of chlorophyll-a in Long Island Sound sediments: a measure of carbon flux and particle reworking. Journal of Marine Research 49: 379-401.

Zanetell, B. A. \& B. L. Peckarsky, 1996. Stoneflies as ecological engineers-hungry predators reduce fine sediments in stream beds. Freshwater Biology 36: 569-577. 